\title{
Vaginal Hypoplasia
}

National Cancer Institute

\section{Source}

National Cancer Institute. Vaginal Hypoplasia. NCI Thesaurus. Code C35415.

A congenital defect in which the vagina is underdeveloped. 